\title{
Introduction: The Second Nordic HPS\&ST Symposium
}

\author{
Ismo T. Koponen
}

Published online: 28 January 2014

(C) Springer Science+Business Media Dordrecht 2014

The symposium concentrated on questions of how to promote better science teaching and better scientific literacy in all levels of education by having lessons informed by the history, philosophy, and sociology of science. In particular, the symposium attempted to discuss and find ways to implement these aspects of knowledge and knowledge formation in teacher-education programs. The collection of papers in this volume, discuss a diversity of topics, but with the common core how philosophy and history of science can be used for the benefits of science teaching. The uses and advantages of such a view are today acknowledged not only in the field of education, but also in the field of cognitively oriented views of learning.

The article Questioning and Experimentation by Arto Mutanen makes an interesting and new contact between Jaakko Hintikka's philosophy and education. This opening is new and with many potential applications in field of science education. In the core of the article is Hintikka's interrogative model of inquiry, with its explicit and well-formed logic of questioning and answering. This model is then used to analyze the learning process. The insights contained in this work show in very illuminating way, how philosophy of science can act as a source of innovation in teaching.

The contributions, Consolidating Pre-service Physics Teachers' Subject Matter Knowledge Using Didactical Reconstructions by Terhi Mäntylä and Maija Nousiainen, and How to Use Historical Approach to Teach Nature of Science in Chemistry Education by Simo Tolvanen, Jan Jansson Veli-Matti Vesterinen and Maija Aksela, come from the research groups of Faculty of Science, Helsinki University, and both describe those innovations and practical renovations which have been done in teacher education inspired by history and philosophy in science. The article by Mäntylä and Nousiainen describes approaches used in physics teacher education, and based on certain didactical reconstruction used to emphasize the epistemological aspects of science. The authors discuss

This special issue contains a selection of reviewed and revised papers presented at the Second Nordic Symposium on Philosophy and History of Science in Science Teaching held October 2012 in the Department of Physics, University of Helsinki, Finland.

I. T. Koponen ( $₫)$

Department of Physics, University of Helsinki, Helsinki, Finland

e-mail: ismo.koponen@helsinki.fi 
how the approach has helped to consolidate the subject content knowledge of teacher. The other article by Tolvanen et al. discusses approach that is used in chemistry teacher education, focusing on Nature of Science (NOS). In the article, the authors describe a 25 lesson plans from four different projects, with a purpose to describe how NOS content is included as part of practical teaching, as well as the historical experiments and narratives can used. They also introduce several suggestions on the successful design of lesson plans utilizing historical approach. Both articles are encouraging examples how research in HPS can impact on learning and instruction.

The importance of history and philosophy of science for developing instructional approaches is exemplified also in the article Comparing Teaching Approaches About Maxwell's Displacement Current by Ricardo Karam, Debora Coimbra and Mauricio Pietrocola. The article addresses a specific, notoriously difficult topic in teaching electromagnetism. The authors show how the research done by historians and philosophers of science on this very same topic can be used as a stepping stone to understand the many possible ways to interpret and justify the need for the displacement current term. The authors analyze different approaches to justify the term insertion in physics textbooks, as well as four lectures devoted to introduce the topic in undergraduate level given by four different professors. They show, how this kind of analysis helps to design solutions for teaching and learning of the displacement current, and to overcome some know difficulties in it.

While the previously mentioned articles discussed the teaching solutions in the university level, a somewhat different area of learning is addressed in the article The "lifeworld" Earth and a Modelled Earth by Kalle Juuti, where children's conception of Earth is in focus. The viewpoint of the author is based on phenomenological way of thinking, where Earth is considered as material and experiential entity, but not as an object as viewed in science. The author re-analyses the data published in Vosniadou and Brewer's and suggest a new interpretation of this data; the Earth as an infinite surface is the way to experience the Earth. On this basis he concludes that the "lifeworld", and apparently then also the phenomenological approach, should be taken in research into consideration more seriously than usually is done. The suggestions open up new interesting directions for science education research and also remind of the alternatives for the more realistically biased research approaches.

The last article Creating New Technologists of Research in the 1960s: The Case of the Reproduction of Automated Chromatography Specialists and Practitioners by Apostolos Gerontas addresses the field of science education from the angle of history of science and technology. This work reminds us that also the detailed case studies of technological innovations may have important messages on science education. The article provides a view of the history of the gas chromatography instrumentation and shows how its invention also prompted large scale educational efforts for the groups of technologists of the era.

In summary, the collection of the six articles in this special volume gives an interesting and stimulating insight on many different ways the history and philosophy of science can affect and enrich the science education. I hope that this special volume helps and encourages conducting these kinds of studies for the benefit of the educators in future. 